\title{
Silver-Catalyzed Enantioselective Propargylic C-H Bond Amination Through Rational Ligand Design
}

\author{
Minsoo Ju, Emily E. Zerull, Jessica M. Roberts, Minxue Huang, and Jennifer M. Schomaker ${ }^{\star}$ \\ Department of Chemistry, University of Wisconsin-Madison, 1101 University Avenue, Madison, WI 53706, USA
}

\begin{abstract}
Asymmetric C-H amination via nitrene transfer (NT) is a powerful tool for the preparation of enantioenriched amine building blocks from abundant $\mathrm{C}-\mathrm{H}$ bonds. Herein, we report a highly regio- and enantioselective synthesis of $\gamma$-alkynyl $\gamma$-amino alcohol motifs via a silver-catalyzed propargylic $\mathrm{C}-\mathrm{H}$ amination. The protocol was enabled by development of a new bis(oxazoline) (BOX) ligand through a rapid structure-activity relationship (SAR) analysis. The method utilizes readily accessible carbamate ester substrates bearing $\gamma$-propargylic $\mathrm{C}-\mathrm{H}$ bonds and furnishes versatile products in good yields and with excellent enantioselectivity $(90-99 \% e e)$. A putative $\mathrm{Ag}$-nitrene intermediate is proposed to undergo an enantiodetermining hydrogen-atom transfer (HAT) during the C-H amination event. Density functional theory (DFT) calculations were performed to investigate the origin of enantioselectivity in the HAT step.
\end{abstract}

Enantioselective syntheses of $\gamma$-amino alcohols is an attractive goal, as diverse biologically active molecules contain this motif, ${ }^{1}$ including the antibiotics negamycin and nikkomycin $\mathrm{Z}$, 1a-c and the HIV treatments lopinavir and ritonavir. ${ }^{1 \mathrm{e}-\mathrm{g}} \gamma$-Amino alcohols are valuable precursors to $\beta$ amino acids, which can be incorporated into peptides as a strategy to modulate their drug-like properties, ${ }^{2}$ and are also convenient sources of chirality for diverse asymmetric transformations. ${ }^{3}$ A popular strategy to prepare enantioenriched $\gamma$-amino alcohols involves formation of chiral imine or carbonyl intermediates, followed by diastereoselective reduction of the $\mathrm{C}=\mathrm{X}(\mathrm{X}=\mathrm{N}$ or 0$)$ bond. ${ }^{4-9}$ However, these asymmetric Mannich-based ${ }^{4-6}$ or chiral auxiliary-directed ${ }^{7-9}$ strategies require additional chemical steps. The direct asymmetric transformation of $\mathrm{C}-\mathrm{H}$ to $\mathrm{C}-\mathrm{N}$ bonds via transition metal-catalyzed nitrene transfer (NT) offers the potential for streamlined access to $\gamma$-amino alcohols from simple, abundant alcohol precursors. ${ }^{10}$ In 2008, the Blakey and Du Bois groups independently reported the first examples of asymmetric amination of benzylic and allylic $\mathrm{C}-\mathrm{H}$ bonds to furnish enantioenriched $\gamma$-amino alcohols in good ee using chiral Ru and Rh catalysts, respectively (Scheme 1a). ${ }^{11,12}$

Since He's first reports of Ag-catalyzed NT, ${ }^{13}$ we and others have exploited the diverse coordination of $\mathrm{Ag}(\mathrm{I})$ species supported by $\mathrm{sp}^{2} \mathrm{~N}$-coordinating ligands to achieve tunable and predictable NT reactions with excellent control over chemo- and site-selectivity. ${ }^{14,15}$ The flexibility of ligands capable of supporting Ag-catalyzed NT make this metal an ideal platform for developing general catalysts for asymmetric NT reactions. In 2017, we reported the first examples of chemoselective, Ag-catalyzed asymmetric aziridination using a 2,2'-isopropylidenebis[(4S)-4-tert-butyl-2-oxazoline] $\left((S, S)-{ }^{-} \mathrm{Bu}-\mathrm{BOX}\right)$ ligand, ${ }^{15 e}$ while Bach recently disclosed a site- and enantioselective $\mathrm{C}-\mathrm{H}$ amination of 2-quinolones and 2-pyridones catalyzed by a heteroleptic $\mathrm{Ag}(\mathrm{I})$ bis(phenanthroline) complex. ${ }^{16}$ In this communication, we describe coupling the flexibility of silver-catalyzed NT with the rational design of new ligands for the asymmetric amination of propargylic $\mathrm{C}-\mathrm{H}$ bonds (Scheme $1 \mathrm{~b}$ ) to enantioenriched $\gamma$-alkynyl $\gamma$-amino alcohol building blocks.

Several factors were considered in our ligand design. One important issue is site-selectivity, as the putative metal nitrene generated from a carbamate precursor can engage a $\beta$ - or $\gamma-\mathrm{C}\left(s p^{3}\right)-\mathrm{H}$ bond (Scheme 1c) to form either a 5- or 6-member heterocycle en route to 1,2- or 1,3-amino alcohol products. We previously demonstrated that ligand choice is key to achieving tunable catalyst control over ring size, with

Scheme 1. Prior and proposed asymmetric C-H bond amination.

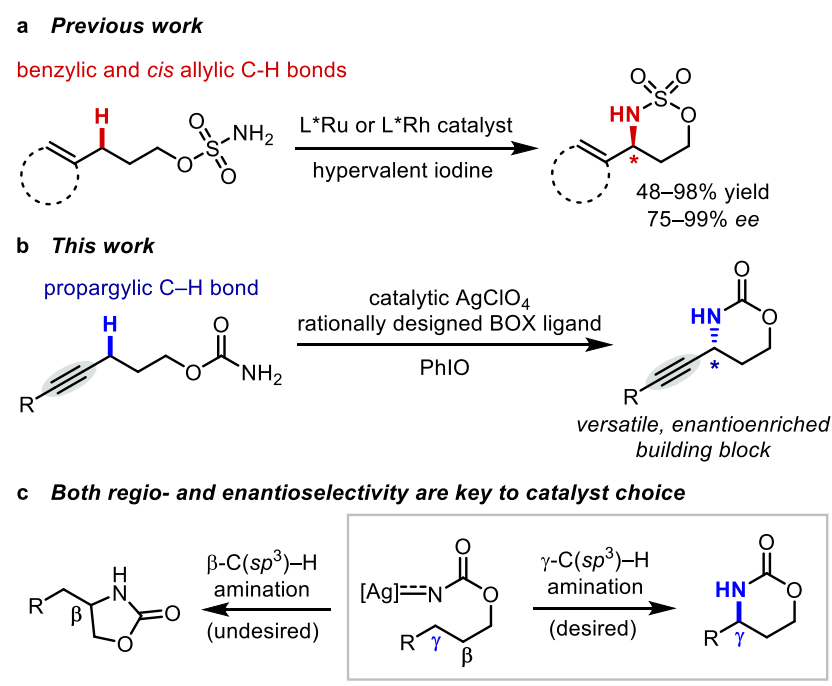

a bidentate, achiral 2,2'-isopropylidenebis[4,4-dimethyl-2oxazoline] (dmBOX) ligand showing a strong preference for $\gamma$-C-H bond amination. ${ }^{15 i} \mathrm{~A}$ second concern involved mini- 
mizing dynamic behavior of the $\mathrm{Ag}(\mathrm{I})$ complex in solution to ensure good transfer of stereochemical information from catalyst to product. Previous diffusion-ordered spectroscopy (DOSY) and variable temperature (VT) NMR studies of a silver complex formed from $\mathrm{dmBOX}$ and $\mathrm{AgClO}_{4}$ revealed no equilibrium between monomeric and dimeric species, and no fluxional behavior of the ligand. ${ }^{15 i}$ Finally, the challenges inherent in differentiating between two prochiral hydrogen atoms on a carbon adjacent to the linear, compact alkyne group required a modular, readily tunable ligand scaffold. Given these considerations, BOX ligands were a logical choice to investigate to achieve our goal of site- and enantioselective propargylic $\mathrm{C}-\mathrm{H}$ bond amination.

Studies were initiated with carbamate ester $\mathbf{1}$, bearing two activated propargylic $\mathrm{C}-\mathrm{H}$ bonds at the $\gamma$-position. A variety of chiral BOX ligands were explored (Figure 1, full details in the Supporting Information) using simple structure-activity
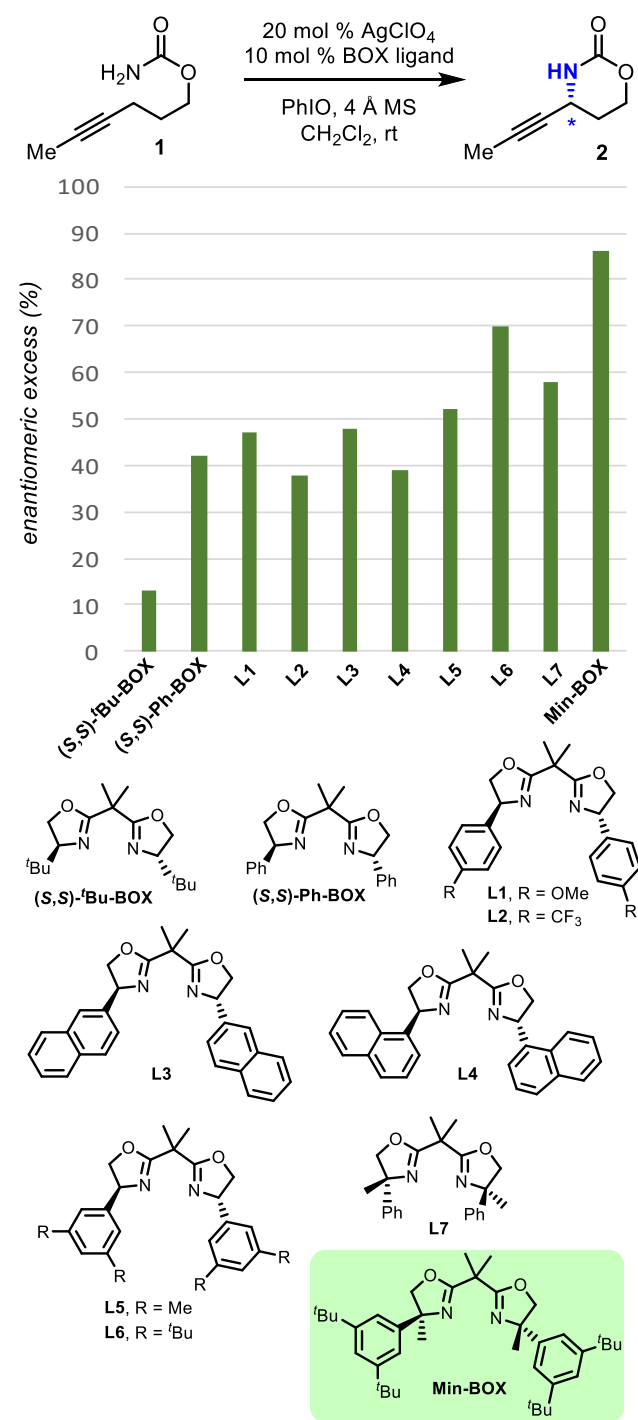

Conditions: 1 (0.1 mmol), $\mathrm{AgClO}_{4}(20 \mathrm{~mol} \%)$, BOX ligand (10 mol \%) PhIO (2 equiv), $4 \AA \mathrm{MS}$ (100 mg), $\mathrm{CH}_{2} \mathrm{Cl}_{2}(2 \mathrm{~mL})$, rt. ee was determined by chiral HPLC analysis after benzylation of product 2 . $\mathbf{L} 7$ produced the opposite enantiomer.

Figure 1. SAR between BOX ligand modification and enantioselectivity in Ag-catalyzed propargylic $\mathrm{C}-\mathrm{H}$ bond amination of $\mathbf{1}$. relationships (SAR) to rapidly identify a promising candidate. Subjecting 1 to conditions for enantioselective aziridination with commercially available $(S, S){ }^{t} \mathrm{Bu}$-BOX ligand, ${ }^{15} \mathrm{e}$ resulted in a good yield of oxazinanone 2 , but in only $13 \%$ $e e$. Interestingly, when the ${ }^{t} \mathrm{Bu}$ was substituted with a $\mathrm{Ph}$ group $((S, S)-\mathrm{Ph}-\mathrm{BOX})$, a significant enhancement to $42 \%$ ee was observed. This was a promising lead, as the aryl-substituted BOX scaffold is highly modular and the steric and electronic features of the ligand can be readily tuned. ${ }^{17}$ Electronic modifications to the aryl groups in $\mathbf{L 1}$ and $\mathbf{L} 2$ were used to probe if substrate-ligand $\pi-\pi$ or metal-ligand cation- $\pi$ interactions might influence $e e . .^{15 f, 18}$ Neither electrondonating (L1) nor electron-withdrawing groups (L2) at the para position had much impact, giving $47 \%$ and $38 \%$ ee, respectively. BOX ligands substituted with a 2-naphthyl (L3) or 1-naphthyl group (L4) indicated increasing steric bulk at the meta position of the aryl group (L3) had a positive impact on the ee of $2(48 \% e e)$, while substitution at the ortho position of the aryl group (L4) decreased the ee to 39\%. Indeed, installation of meta-Me and ${ }^{t} \mathrm{Bu}$ groups on the aromatic ring of BOX ligands L5 and L6 improved the ee significantly, up to $70 \% e e$ in the case of L6. Replacing the hydrogens at the chiral carbons of $(S, S)$-Ph-BOX with Me groups to yield fully substituted carbon centers in $\mathbf{L 7}$ improved ee from $42 \%$ to $58 \%$. Gratifyingly, combining the features that improve ee into a single Min-BOX ligand gave $86 \%$ ee and a near-quantitative yield of $\mathbf{2}$ at room temperature. The $e e$ was further improved at lower temperatures, furnishing up to $90 \% e e$ at $-10^{\circ} \mathrm{C}$ (see the SI for details of optimization).

The beneficial effect of additional substitution at the stereocenter $\alpha$ to the coordinating $N$ atoms in L7 and Min-BOX ligands was at first counterintuitive, as replacing $\mathrm{H}$ with $\mathrm{Me}$ should reduce facial discrimination in the NT event. We hypothesized this modification suppressed detrimental dynamic behavior of the complex by increasing the steric congestion near the silver center. ${ }^{19}$ Previous observations showed certain $\mathrm{N}$-chelating ligands for $\mathrm{Ag}(\mathrm{I})$ lead to equilibrating mixtures of mono- $v$ s. bis-ligated species, as well as monomeric $v s$. dimeric complexes; ${ }^{15 a, 15 i, 19 c}$ the presence of multiple potential catalytic species leads to a loss of selectivity. Indeed, NMR studies of silver complexes supported by $\mathbf{L} 7$ and Min-BOX did not show any equilibrium between mono- and bis-ligated species (see the SI for details). Rather, the data suggested the presence of altered conformer populations in the $\mathrm{Ag}(\mathbf{L} 7)$ OTf complex at different temperatures (Figure 2a). The VT ${ }^{1} \mathrm{H}$ NMR spectra of $\mathrm{Ag}(\mathbf{L} 7) \mathrm{OTf}$ in $\mathrm{CD}_{2} \mathrm{Cl}_{2}(5 \mathrm{mM})$ showed substantial changes in the chemical shifts of the diastereotopic protons $\mathrm{H}_{\mathrm{a}}$ and $\mathrm{H}_{\mathrm{a}^{\prime}}$ and the aromatic protons as the temperature was decreased, while no changes in chemical shift were observed in $\mathrm{Ag}$ complexes supported by BOX ligands lacking a fully substituted carbon center. Although individual conformer signals of $\mathrm{Ag}(\mathbf{L} 7) \mathrm{OTf}$ were not resolved even at $-90{ }^{\circ} \mathrm{C}$, this implies a relatively high energy barrier for the rotations around single bond(s). ${ }^{20}$ DFT calculations were carried out on truncated mono-oxazoline models to shed further insight into the influence of the fully substituted carbon center on bond rotation (Figure 2b, see the SI for details). Relaxed surface scans were conducted by rotating the $\mathrm{N}-\mathrm{C}-\mathrm{C}-\mathrm{C}$ dihedral angle $\left(10^{\circ}\right.$ increments, 36 steps) to assess the energetic penalty of rotating the aromatic ring $\left(\Delta \mathrm{G}_{\text {rot }}\right)$. Installation of the $\alpha$-Me group (M2) increases bond rotation energy relative to the 

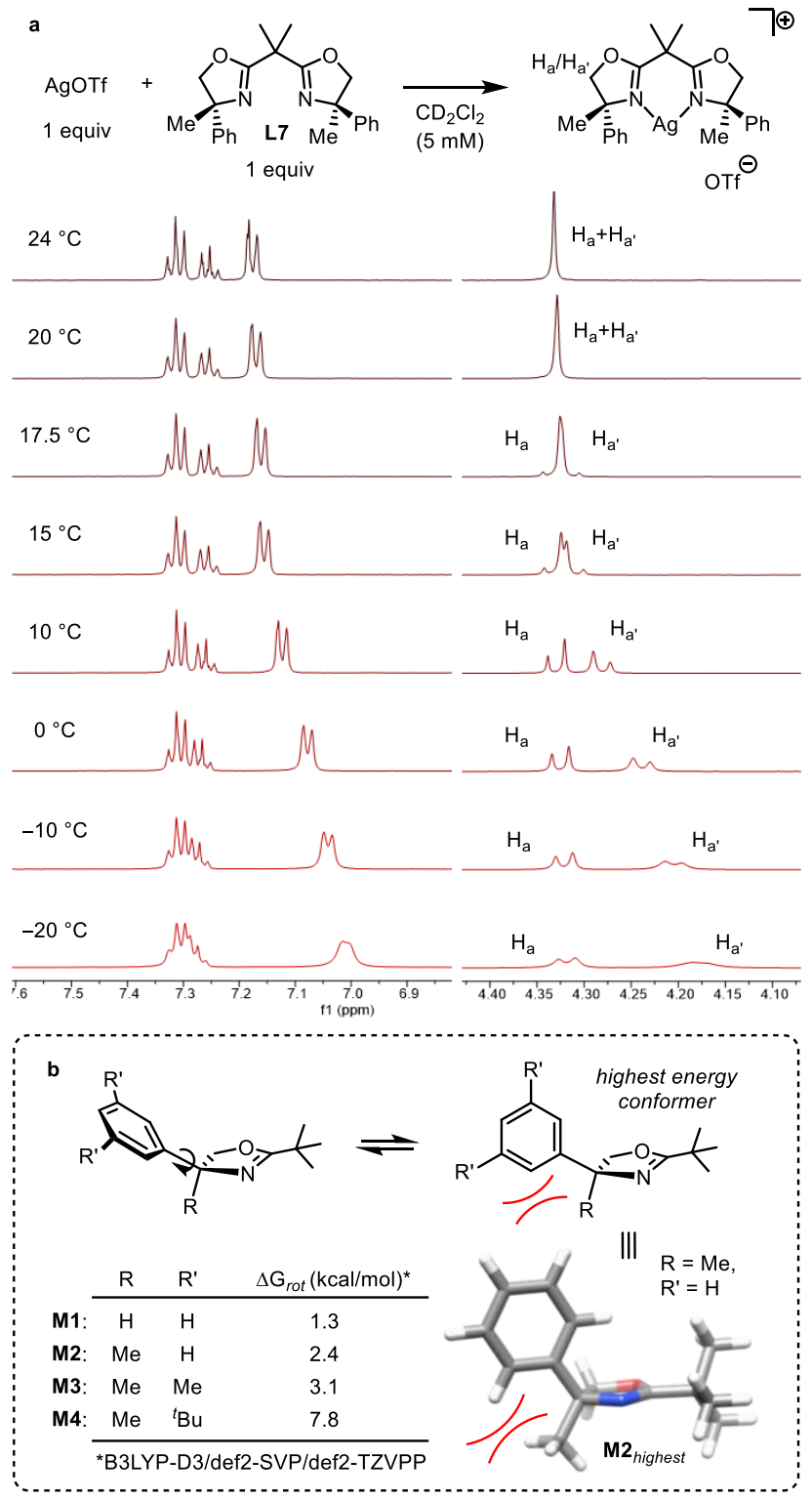

Figure 2. Effect of the additional Me substitution in the ligand. (a) VT-NMR studies of $[\mathrm{Ag}(\mathbf{L 7})]$ OTf complex. (b) Increased rotational barrier $\left(\Delta \mathrm{G}_{\text {rot }}\right)$ for the Ar group, as supported by DFT calculations.

M1 model $\left(\Delta \Delta \mathrm{G}_{\text {rot }}=+1.1 \mathrm{kcal} / \mathrm{mol}\right.$ from $\mathbf{M} 1$ to $\left.\mathbf{M} 2\right)$. Successful bond rotation with this increased steric hindrance involves placing the ortho-proton within $\sim 2.2-2.4 \AA$ from two of the $\alpha$-Me protons. In agreement with the observed ee enhancement, introduction of meta-Me substitution on the aryl ring increased the bond rotation energy to $3.1 \mathrm{kcal} / \mathrm{mol}$ (M3). Further steric crowding with meta-tBu groups gave a $7.8 \mathrm{kcal} / \mathrm{mol}$ bond rotation energy (M4), nearly 6.5 $\mathrm{kcal} / \mathrm{mol}$ greater than the M1 model. We postulate the increased rotational barrier introduced by the $\alpha$-Me group substitution and the restricted rotation of the aryl ring in BOX ligands L7 and Min-BOX rigidify the enantiodetermining transition state (TS) and enhance asymmetric induction.

With optimized conditions in hand, the scope of the reaction was explored (Figure 3). In general, substrates containing bulky alkyl or aryl substitution at the distal carbon of the alkyne gave excellent yields and $e e$. For example, altering the distal R group from the initial methyl group in 2 to bulkier substituents, such as $n$-pentyl (3), $i$-propyl (4) or $t$-butyl groups (5), resulted in increased ee to $94-96 \%$. Notably, the enantioselectivities were not affected by electronic modifications to the alkyne precursors. Both $\mathbf{6}(\mathrm{R}=\mathrm{TMS})$ and $\mathbf{7}(\mathrm{R}$ $=\mathrm{CF}_{3}$ ) gave excellent $e$, although an increased catalyst loading was required for the $\mathrm{CF}_{3}$-substituted alkyne 7 , due to slow conversion. These results helped to rule out the possibility of alkyne-Ag interactions playing a critical role in the enantiodetermining step. Carbamate esters containing a $\mathrm{Ph}$ group attached to the distal alkyne carbon (8), as well as derivatives possessing both electron-donating ( 9 and $\mathbf{1 1})$ and an electron-withdrawing groups $(\mathbf{1 0})$ at the para-position were successfully transformed into the corresponding oxazinanones in high ee (92-93\%). Addition of -OMe at the meta-position of the Ar substituent was tolerated (12), while ortho-Me-substitution slightly diminished the ee (13). Alkynes bearing heterocyclic groups, such as a furan (14) and a thiophene (15), were also tolerated under the reaction conditions.

The impact of the steric bulk of the substituents at the distal carbon of the alkyne precursors on ee was further examined through linear free-energy relationships (LFER) using the steric parameters and modified Taft equation developed by Charton. ${ }^{21}$ The equation $\log \left(k / k_{0}\right)=\psi v$ describes a relationship between the relative rate $\left(k / k_{0}\right)$ and steric parameters $(v)$, with $v$ defined from measuring steric effects in the rates of methyl ester hydrolysis. The $k / k_{0}$ is equal to the enantiomeric ratio $(e r)$ when evaluating an asymmetric reaction; therefore, $\log (e r)$ is proportional to the product of $\psi$ (the sensitivity factor) and $v .^{22} \mathrm{~A}$ LFER with a good correlation $\left(\mathrm{R}^{2}=0.82\right)$ was observed when $\log (e r)$ was plotted $v s$. $v$ values for 2-5 and 8. The positive sensitivity factor $\psi$ and high correlation with Charton's steric parameters indicate that larger groups on the distal alkyne carbon should yield higher $e e$. To test this prediction, a substrate containing an alkyne protected with a $t$-butyldiphenylsilyl (TBDPS) group was prepared and subjected to asymmetric $\mathrm{C}-\mathrm{H}$ amination to give $\mathbf{1 6}$ in $99 \%$ ee. The oxazinanone $\mathbf{1 6}$ was subjected to a mild ring-opening conditions to give a $92 \%$ NMR yield of the corresponding $\gamma$-amino alcohol, while preserving the TBDPS group. The absolute configuration of $\mathbf{1 6}$ was determined to be $(R)$ by X-ray crystallography; other product configurations assigned by analogy to $\mathbf{1 6}$. Additionally, substrates bearing an alkyl ether (17) or an alkyl chloride (18) were well-tolerated in this chemistry, furnishing excellent ee of $93 \%$ and $92 \%$, respectively. Substitution in the tether was also possible at both the $\alpha$ - and $\beta$-positions and had no detrimental effect on the enantioselectivity of the reaction (19-20, 95-96\% ee). The carbamate ester precursor to 20 is particularly noteworthy, as it is derived from a tertiary alcohol that does not effectively form the sulfamate precursor required for Ru- and Rh-catalyzed NT. ${ }^{11,12}$ While $\alpha$-substitution in $\mathbf{2 0}$ led to a drop in conversion under standard conditions, a higher catalyst loading restored reactivity; this approach is also effective for substrates with electron-poor propargylic $\mathrm{C}-\mathrm{H}$ bonds, such as the precursor to $\mathbf{7}$.

Previously reported experimental and computational studies on Ag-catalyzed NT reactions suggest the mechanistic pathway proposed in Figure 4a. The carbamate ester 


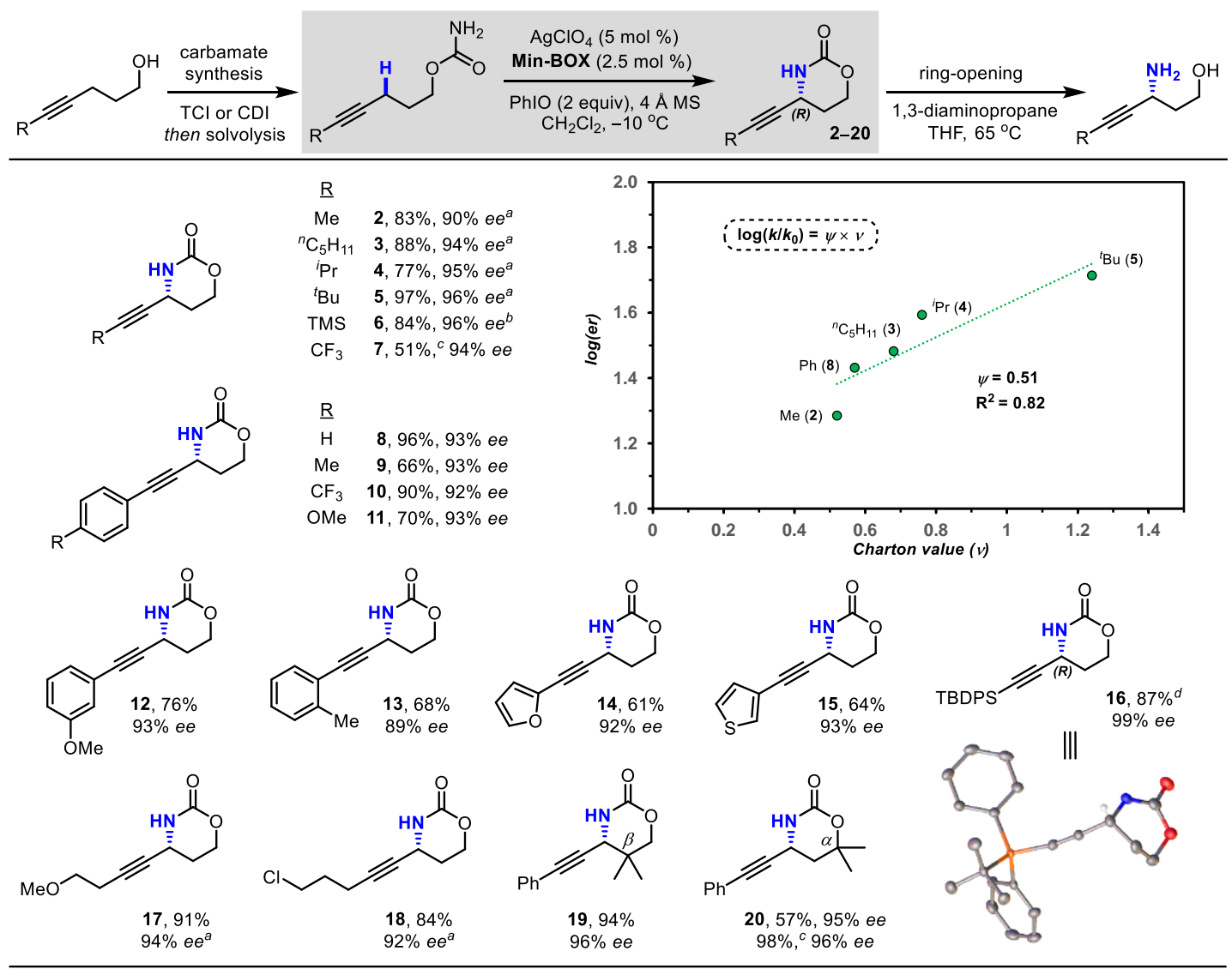

Conditions: carbamate ester $(0.2 \mathrm{mmol}), \mathrm{AgClO}_{4}(5 \mathrm{~mol} \%)$, Min-BOX $(2.5 \mathrm{~mol} \%)$, PhlO (2 equiv), $4 \AA \mathrm{MS}(200 \mathrm{mg}), \mathrm{CH}_{2} \mathrm{Cl}_{2}(4 \mathrm{~mL}),-10{ }^{\circ} \mathrm{C}$. Isolated yields indicated; ee determined by chiral HPLC analysis. ${ }^{a}$ ee determined after benzylation. ${ }^{b}$ ee determined after benzoylation. ${ }^{c}$ Reaction used $2 x$ catalyst loading $\left(10 \mathrm{~mol} \% \mathrm{AgClO}_{4} / 5 \mathrm{~mol} \%\right.$ Min-BOX). ${ }^{d}$ The free 1,3-amino alcohol was obtained in $92 \% \mathrm{NMR}$ yield after deprotection with 1,3-diaminopropane (20 equiv), THF $(0.1 \mathrm{M}), 65{ }^{\circ} \mathrm{C}$.

Figure 3. Substrate scope and LFER study of Ag-catalyzed enantioselective amination of propargylic C-H bonds

nitrene precursor A initially undergoes ligand exchange with the iodosobenzene (PhIO) oxidant to form an iminoiodinane species B (Figure $4 \mathrm{a}$ ). ${ }^{15 \mathrm{e}, 23}$ A silver-nitrene complex $\mathbf{C}$ is generated by reacting the iminoiodinane species with a chiral Ag(I) catalyst. According to our previous DFT studies, the reactive intermediate $\mathbf{C}$ is best described as $\mathrm{Ag}(\mathrm{II})-$ nitrene radical anion, which abstracts a prochiral propargylic hydrogen in a hydrogen atom transfer (HAT) step, followed by a rapid radical recombination (RR) step. ${ }^{14 d, 14 f, 18 c}$ The radical species is not a stationary point on the potential energy surface, as the RR step displays no energy barrier; experimentally, no radical intermediates are intercepted or trapped. Previous observations confirm the $\mathrm{C}-\mathrm{H}$ amination is stereoretentive, further supporting the rapid nature of the RR step ${ }^{15 i-j, 19 b}$ and suggesting the initial HAT is the enantiodetermining step in the asymmetric $\mathrm{C}-\mathrm{H}$ bond amination.

In order to probe the origin of enantioselectivity in the HAT, TS modeling of the two prochiral pathways was conducted on the propargylic $\mathrm{C}-\mathrm{H}$ amination of carbamate ester $\mathbf{1}$ using a silver catalyst supported by a model BOX ligand L8 (truncated from Min-BOX: meta $^{-t} \mathrm{Bu} \rightarrow \mathrm{Me}$ ) (Figure 4b). The silver complex $A g(\mathbf{L 8})^{+}$in the calculations was supported by a single BOX ligand, as DOSY NMR experiments show Ag-BOX complexes in solution are monomeric. ${ }^{15 i, 24} \mathrm{We}$ were delighted to find the DFT calculations successfully predicted the observed $(R)$ absolute configuration, with the pro- $R$ pathway favored by $1.7 \mathrm{kcal} / \mathrm{mol}$. The pro- $R$ TS places the substrate tail in close proximity to the para-position of the aryl ring (2.794 $\AA$ ) to avoid steric interactions with the fully substituted carbon center. The alkyne position faces away from the ligand scaffold, with an alkyne substituent...meta-Me distance of (2.778 $\mathrm{A}$ ). Conversely, the disfavored pro- $S$ TS places the alkyne tail near the ortho-proton of the aryl ring (2.546 $\AA$ ), with an alkyne Me...meta-Me distance of $3.235 \AA$. This alkyne orientation introduces steric interactions between the substrate tail and the $\alpha$-Me group of the fully substituted carbon center (2.884 $\AA$ ), which is absent in the pro- $R$ pathway. Though these TS models differ in their steric interactions, near-linear $\mathrm{N} \cdots \mathrm{H} \cdots \mathrm{C}$ geometries were observed for both the pro- $R\left(158.3^{\circ}\right)$ and pro- $S$ $\left(161.7^{\circ}\right)$ TS in the HAT, consistent with our previous computational studies. ${ }^{15 i}$ In accordance with the anticipated rigidity of L8, the aryl ring rotations from pro- $R$ to pro- $S$ only deviate up to $7.5^{\circ}$; indeed, introduction of the fully substituted carbon center and the meta alkyl substitution in the aryl ring of the Min-BOX reduces the ability of the ligand scaffold to minimize steric interactions in the disfavored pro-S pathway.

In conclusion, we report the first general catalyst for intramolecular, enantioselective propargylic $\mathrm{C}-\mathrm{H}$ amination proceeding via an Ag-catalyzed NT pathway. A new MinBOX ligand was rationally designed to transform carbamate 


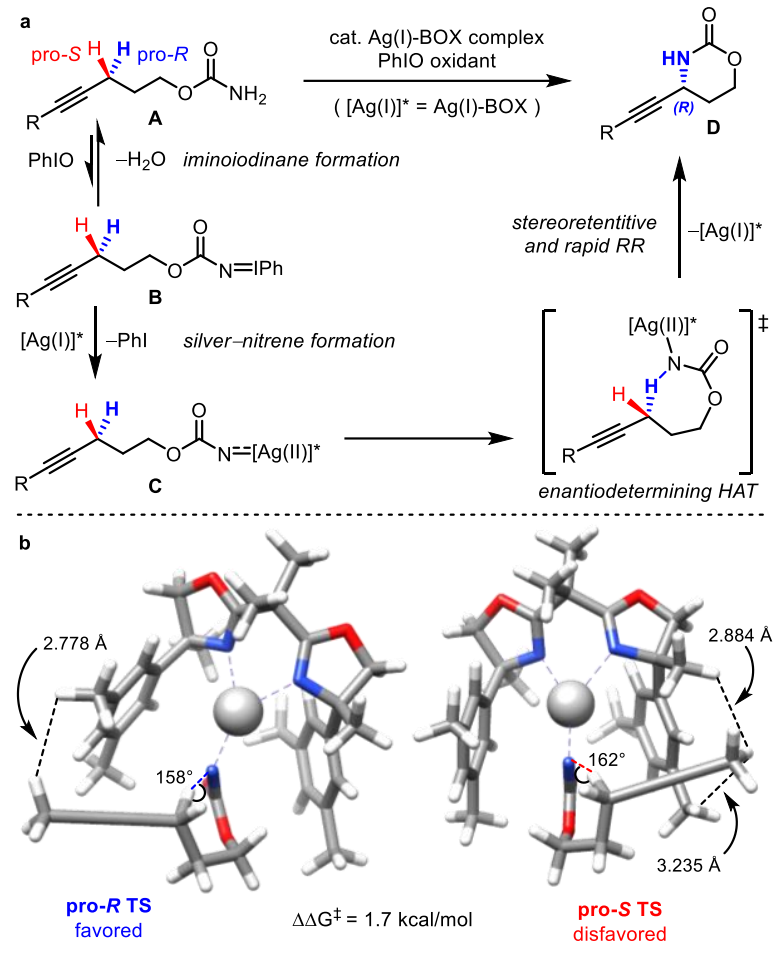

Figure 4. (a) Proposed mechanism of Ag-catalyzed enantioselective propargylic C-H amination. (b) B3LYP-D3/def2-SVP/def2TZVPP transition state models of pro- $R$ and pro- $S$ HAT pathways employing substrate $\mathbf{1}$ and $\operatorname{Ag}(\mathbf{L 8})^{+}$complex.

ester substrates bearing two prochiral $\gamma$-propargylic $\mathrm{C}-\mathrm{H}$ bonds to $\gamma$-amino alcohol motifs in good yields and ee. Charton's modified Taft equation and steric parameters established a LFER between the size of groups on the distal alkyne carbon and the $e e$ of the NT. DFT calculations further validated that the design features introduced into Min-BOX effectively differentiate between the pro- $R$ and pro- $S$ protons during the enantiodetermining HAT step. The oxazinanones generated from this method are easily deprotected and derivatized to enantioenriched amino alcohols that can serve as useful building blocks for diverse molecules, including the platelet aggregation inhibitor, Xemilofiban, ${ }^{25}$ anti-malarial falcipain-2 inhibitors, ${ }^{26}$ and other amines.

\section{ASSOCIATED CONTENT}

Characterization data, optimization tables, and additional substrates/catalysts are included in the supplementary materials, which are available free of charge via the Internet at http://pubs.acs.org.

\section{AUTHOR INFORMATION}

*schomakerj@chem.wisc.edu

\section{Author Contributions}

The manuscript was written through contributions of all authors. All authors have given approval to the final version of the manuscript.

\section{Funding Sources}

J.M.S. is grateful to the NSF 1664374 for financial support of this research. The Paul Bender Chemistry Instrumentation
Center was supported by: Thermo Q ExactiveTM Plus by NIH 1S10 0D020022-1; Bruker Quazar APEX2 and Bruker Avance500 by a generous gift from Paul J. and Margaret M. Bender; Bruker Avance-600 by NIH S10 0K012245; Bruker Avance-400 by NSF CHE-1048642 and the University of Wisconsin-Madison; Varian Mercury-300 by NSF CHE-0342998.

\section{ACKNOWLEDGMENT}

Dr. Charles G. Fry and Dr. Heike Hofstetter at UW-Madison are thanked for valuable discussions about NMR techniques. Dr. Martha M. Vestling at UW-Madison is thanked for help with mass spectrometry characterization. UCSF Chimera is developed by the Resource for Biocomputing, Visualization, and Informatics at the University of California, San Francisco (supported by NIH P41-GM103311).

\section{REFERENCES}

1. For selected examples, see: a) Zhu, L.; Hong, R. Pursuing effective Gram-negative antibiotics: The chemical synthesis of negamycin. Tetrahedron Lett. 2018, 59, 2112-2127. b) Taguchi, A.; Hamada, K.; Hayashi, Y. Chemotherapeutics overcoming nonsense mutation-associated genetic diseases: medicinal chemistry of negamycin. J Antibiot. 2018, 71, 205-214. c) Nix, D. E.; Swezey, R. R.; Hector, R.; Galgiani, J. N. Pharmacokinetics of nikkomycin $\mathrm{Z}$ after single rising oral doses. Antimicrob. Agents Chemother. 2009, 53, 2517-21. d) Yasuda, S.; Kitagawa, H.; Ueno, M.; Ishitani, H.; Fukasawa, M.; Nishijima, M.; Kobayashi, S.; Hanada, K. A novel inhibitor of ceramide trafficking from the endoplasmic reticulum to the site of sphingomyelin synthesis. J. Biol. Chem. 2001, 276, 43994-4002. e) Sham, H. L.; Zhao, C.; Li, L.; Betebenner, D. A.; Saldivar, A.; Vasavanonda, S.; Kempf, D. J.; Plattner, J. J.; Norbeck, D. W. Novel lopinavir analogues incorporating non-aromatic P-1 side chains-Synthesis and structure-activity relationships. Bioorg. Med. Chem. Lett. 2002, 12, 31013103. f) Kempf, D. J.; Sham, H. L.; Marsh, K. C.; Flentge, C. A.; Betebenner, D.; Green, B. E.; McDonald, E.; Vasavanonda, S.; Saldivar, A.; Wideburg, N. E.; Kati, W. M.; Ruiz, L.; Zhao, C.; Fino, L.; Patterson, J.; Molla, A.; Plattner, J. J.; Norbeck, D. W. Discovery of ritonavir, a potent inhibitor of HIV protease with high oral bioavailability and clinical efficacy. J. Med. Chem. 1998, 4, 602-17.g) Haight, A. R.; Stuk, T. L.; Allen, M. S.; Bhagavatula, L.; Fitzgerald, M.; Hannick, S. M.; Kerdesky, F. A.; Menzia, J. A.; Parekh, S. I.; Robbins, T. A.; Scarpetti, D.; Tien, J.-H. Reduction of an enaminone: Synthesis of the diamino alcohol core of ritonavir. Org. Proc. Res. Develop. 1999, 3, 94-100.

2. Cabrele, C.; Martinek, T. A.; Reiser, O.; Berlicki, L. Peptides containing beta-amino acid patterns: challenges and successes in medicinal chemistry. J. Med. Chem. 2014, 57, 9718-39.

3. Lait, S.; Rankic, D.; Keay, B. A. 1,3-aminoalcohols and their derivatives in asymmetric organic synthesis. Chem Rev 2007, 107, 76796.

4. Josephsohn, N. S.; Snapper, M. L.; Hoveyda, A. H. Ag-catalyzed asymmetric Mannich reactions of enol ethers with aryl, alkyl, alkenyl, and alkynyl imines. J. Am. Chem. Soc. 2004, 126, 3734-5.

5. Millet, R.; Traff, A. M.; Petrus, M. L.; Backvall, J. E. Enantioselective synthesis of syn- and anti-1,3-aminoalcohols via $\beta$-aminoketones and subsequent reduction/dynamic kinetic asymmetric transformations. J. Am. Chem. Soc. 2010, 132, 15182-4.

6. Fustero, S.; Jimenez, D.; Sanz-Cervera, J. F.; Sanchez-Rosello, M.; Esteban, E.; Simon-Fuentes, A. Highly enantioselective synthesis of fluorinated $\gamma$-amino alcohols through proline-catalyzed crossMannich reaction. Org. Lett. 2005, 7, 3433-6.

7. Kochi, T.; Tang, T. P.; Ellman, J. A. Asymmetric synthesis of synand anti-1,3-amino alcohols. J. Am. Chem. Soc. 2002, 124, 6518-9.

8. Kochi, T.; Tang, T. P.; Ellman, J. A. Development and application of a new general method for the asymmetric synthesis of syn- and anti-1,3-amino alcohols. J. Am. Chem. Soc. 2003, 125, 11276-82. 
9. Davis, F. A.; Gaspari, P. M.; Nolt, B. M.; Xu, P. Asymmetric synthesis of acyclic 1,3-amino alcohols by reduction of $N$-sulfinyl betaamino ketones. Formal synthesis of (-)-pinidinol and (+)- epipinidinol. J. Org. Chem. 2008, 73, 9619-26.

10. For selected references of asymmetric nitrene transfer with other precursors not leading to amino alcohol products, see: a) (a) Park, Y.; Chang, S. Asymmetric formation of $\gamma$-lactams via C-H amidation enabled by chiral hydrogen-bond-donor catalysts. Nat. Catal. 2019, 2, 219-227. b) Wang, H.; Park, Y.; Bai, Z.; Chang, S.; He, G.; Chen, G. Iridium-catalyzed enantioselective $\mathrm{C}\left(\mathrm{sp}^{3}\right)-\mathrm{H}$ amidation controlled by attractive noncovalent interactions. J. Am. Chem. Soc. 2019, 141, 7194-7201. c) Hu, Y.; Lang, K.; Li, C.-Q.; Gill, J. B.; Kim, I.; Lu, H.-J.; Fields, K. B.; Marshall, M. K.; Cheng, Q.-G.; Cui, X.; Wojtas, L.; Zhang, X. P. Enantioselective Radical Construction of 5-Membered Cyclic Sulfonamides by Metalloradical C-H Amination. J. Am. Chem. Soc. 2019, 141, 18160-18169. d) Li, C.-Q.; Lang, K.; Lu, H,-J.; Hu, Y.; Cui, X.; Wojtas, L.; Zhang, X. P. Catalytic Radical Process for Enantioselective Amination of $\mathrm{C}\left(\mathrm{sp}^{3}\right)-\mathrm{H}$ Bonds. Angew. Chem. Int. Ed. 2018, 57, 16837-16841.

11. Milczek, E.; Boudet, N.; Blakey, S. Enantioselective C-H amination using cationic ruthenium(II)-pybox catalysts. Angew. Chem. Int. Ed. 2008, 47, 6825-8.

12. Zalatan, D. N.; Du Bois, J. A chiral rhodium carboxamidate catalyst for enantioselective C-H amination. J. Am. Chem. Soc. 2008, 130, 9220-1.

13. a) Cui, Y.; He, C. Efficient aziridination of olefins catalyzed by a unique disilver(I) compound. J. Am. Chem. Soc. 2003, 125, $16202-$ 3. b) Cui, Y.; He, C. A silver-catalyzed intramolecular amidation of saturated C-H bonds. Angew. Chem. Int. Ed. 2004, 43, 4210-2. c) Li, Z.; Capretto, D. A.; Rahaman, R.; He, C. Silver-catalyzed intermolecular amination of C-H groups. Angew. Chem. 2007, 119, 5276-5278.

14. For selected references, see: a) Llaveria, J.; Beltran, A.; Diaz-Requejo, M. M.; Matheu, M. I.; Castillon, S.; Pérez, P. J. Efficient silvercatalyzed regio- and stereospecific aziridination of dienes. Angew. Chem. Int. Ed. 2010, 49, 7092-5. b) Maestre, L.; Sameera, W. M.; Diaz-Requejo, M. M.; Maseras, F.; Pérez, P. J. A general mechanism for the copper- and silver-catalyzed olefin aziridination reactions: concomitant involvement of the singlet and triplet pathways. J. Am. Chem. Soc. 2013, 135, 1338-48. c) Mak, C. L.; Bostick, B. C.; Yassin, N. M.; Campbell, M. G. Argentophilic interactions in solution: An EXAFS study of silver(I) nitrene transfer catalysts. Inorg. Chem. 2018, 57, 5720-5722. d) Elkoush, T.; Mak, C. L.; Paley, D. W.; Campbell, M. G. Silver(II) and silver(III) intermediates in alkene aziridination with a dinuclear silver(I) nitrene transfer catalyst. ACS Catalysis 2020, 4820-4826.

15. For selected references, see: a) Rigoli, J. W.; Weatherly, C. D.; Alderson, J. M.; Vo, B. T.; Schomaker, J. M. Tunable, chemoselective amination via silver catalysis. J. Am. Chem. Soc. 2013, 135, 1723841. b) Scamp, R. J.; Rigoli, J. W.; Schomaker, J. M. Chemoselective silver-catalyzed nitrene insertion reactions. Pure Appl. Chem. 2014, 86, 381-393. c) Scamp, R. J.; Jirak, J. G.; Dolan, N. S.; Guzei, I. A.; Schomaker, J. M. A general catalyst for site-selective $\mathrm{C}\left(\mathrm{sp}^{3}\right)-\mathrm{H}$ bond amination of activated secondary over tertiary alkyl C( $\left.\mathrm{sp}^{3}\right)-\mathrm{H}$ bonds. Org. Lett. 2016, 18, 3014-7. d) Dolan, N. S.; Scamp, R. J.; Yang, T.; Berry, J. F.; Schomaker, J. M. Catalyst-controlled and tunable, chemoselective silver-catalyzed intermolecular nitrene transfer: Experimental and computational studies. J. Am. Chem. Soc. 2016, 138, 14658-14667. e) Ju, M.; Weatherly, C. D.; Guzei, I. A.; Schomaker, J. M. Chemo- and enantioselective intramolecular silver-catalyzed aziridinations. Angew. Chem. Int. Ed. 2017, 56, 9944-9948. f) Huang, M.; Yang, T.; Paretsky, J. D.; Berry, J. F.; Schomaker, J. M. Inverting steric effects: Using "attractive" noncovalent interactions to direct silver-catalyzed nitrene transfer. J. Am. Chem. Soc. 2017, 139, 17376-17386. g) Corbin, J. R.; Schomaker, J. M. Tunable differentiation of tertiary $\mathrm{C}-\mathrm{H}$ bonds in intramolecular transition metalcatalyzed nitrene transfer reactions. Chem. Commun. 2017, 53,
4346-4349. h) Alderson, J. M.; Corbin, J. R.; Schomaker, J. M. Tunable, chemo- and site-selective nitrene transfer reactions through the rational design of silver(I) catalysts. Acc. Chem. Res. 2017, 50, 2147-2158. i) Ju, M.; Huang, M.; Vine, L. E.; Dehghany, M.; Roberts, J. M.; Schomaker, J. M. Tunable catalyst-controlled syntheses of $\beta$ and $\gamma$-amino alcohols enabled by silver-catalysed nitrene transfer. Nature Catal. 2019, 2, 899-908. j) Alderson, J. M.; Phelps, A. M.; Scamp, R. J.; Dolan, N. S.; Schomaker, J. M. Ligand-controlled, tunable silver-catalyzed C-H amination. J. Am. Chem. Soc. 2014, 136, 16720-3.

16. Annapureddy, R.; Jandl, C.; Bach, T. A chiral phenanthroline ligand with a hydrogen bonding site: Application to the enantioselective amination of methylene groups. J. Am. Chem. Soc. 2020, 142, 7374-78.

17. Desimoni, G.; Faita, G.; Jorgensen, K. A. C(2)-symmetric chiral bis(oxazoline) ligands in asymmetric catalysis. Chem. Rev. 2006, 106, 3561-651.

18. Wang, H.; Park, Y.; Bai, Z.; Chang, S.; He, G.; Chen, G. Iridiumcatalyzed enantioselective $\mathrm{C}\left(\mathrm{sp}^{3}\right)-\mathrm{H}$ amidation controlled by attractive noncovalent interactions. J. Am. Chem. Soc. 2019, 141, 7194-7201.

19. a) Huang, M.; Corbin, J. R.; Dolan, N. S.; Fry, C. G.; Vinokur, A. I.; Guzei, I. A.; Schomaker, J. M. Synthesis, characterization, and variable-temperature NMR studies of silver(I) complexes for selective nitrene transfer. Inorg. Chem. 2017, 56, 6725-6733. b) Schomaker, J. M.; Huang, M.; Paretsky, J. Rigidifying $\mathrm{Ag}(\mathrm{I})$ complexes for selective nitrene transfer. ChemCatChem 2020, doi.org/10.1002/ cctc.2020 00336. c) Weatherly, C.; Alderson, J. M.; Berry, J. F.; Hein, J. E.; Schomaker, J. M. Catalyst-controlled nitrene transfer by tuning metal:ligand ratios: Insight into the mechanisms of chemoselectivity. Organometallics 2017, 36, 1649-1661.

20. Jackman, L. M.; Sternhell, S. Application of Nuclear Magnetic Resonance Spectroscopy in Organic Chemistry. 1969.

21. a) Charton, M. Nature of the ortho effect. II. Composition of the Taft steric parameters. J. Am. Chem. Soc. 1969, 91, 615-618. b) Charton, M. Steric effects. I. Esterification and acid-catalyzed hydrolysis of esters. J. Am. Chem. Soc. 1975, 97, 1552-1556. c) Charton, M. Steric effects. II. Base-catalyzed ester hydrolysis. J. Am. Chem. Soc. 1975, 97, 3691-3693. d) Charton, M. Steric effects. 7. Additional V constants. J. Org. Chem. 1976, 41, 2217-2220.

22. Sigman, M. S.; Miller, J. J. Examination of the role of Taft-type steric parameters in asymmetric catalysis. J. Org. Chem. 2009, 74, 7633-43.

23. Fiori, K. W.; Espino, C. G.; Brodsky, B. H.; Du Bois, J. A mechanistic analysis of the Rh-catalyzed intramolecular $\mathrm{C}-\mathrm{H}$ amination reaction. Tetrahedron 2009, 65, 3042-3051.

24. Ma, S.; Wu, S. Synthesis and structural characterization of infinite single-stranded coordination polymers of optically active bis(oxazoline) ligands with silver trifluoromethanesulfonate. New J. Chem. 2001, 25, 1337-1341.

25. a) Boys, M. L. A synthesis of the platelet aggregation inhibitor xemilofiban from L-aspartic acid. Confirmation of the absolute configuration. Tetrahedron Lett. 1998, 39, 3449-3450. b) Cossy, J.; Schmitt, A.; Cinquin, C.; Buisson, D.; Belotti, D. A very short, efficient and inexpensive synthesis of the prodrug form of SC-54701A a platelet aggregation inhibitor. Bioorg. Med. Chem. Lett. 1997, 7, 1699-1700. c) Awasthi, A. K.; Boys, M. L.; Cain-Janicki, K. J.; Colson, P. J.; Doubleday, W. W.; Duran, J. E.; Farid, P. N. Practical enantioselective synthesis of $\beta$-substituted- $\beta$-amino esters. J. Org. Chem. 2005, 70, 5387-97.

26. Ettari, R.; Nizi, E.; Di Francesco, M. E.; Dude, M. A.; Pradel, G.; Vicik, R.; Schirmeister, T.; Micale, N.; Grasso, S.; Zappala, M. Development of peptidomimetics with a vinyl sulfone warhead as irreversible falcipain-2 inhibitors. J. Med. Chem. 2008, 51, 988-96. 


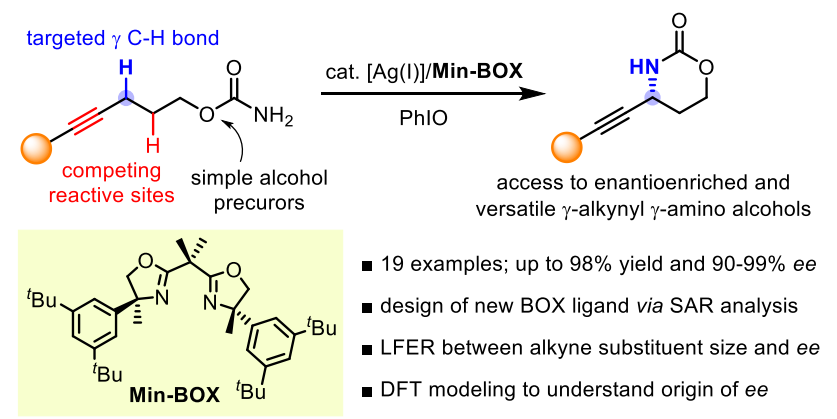

